\title{
MODELING, ANALYZING AND SAFETY ASPECTS OF TORSION AND NOISE EFFECTS ON ROUND MILD STEEL SHAFTS BY RESPONSE SURFACE METHODOLOGY
}

\author{
N.Boominathan ${ }^{1}$, G.K.Vijayaraghavan ${ }^{2}$, R.Kathiravan ${ }^{3}$ \\ ${ }^{1}$ Research scholar, Periyar Maniammai University, Vallam, Thanjavur, Tamilnadu. \\ ${ }^{2}$ Principal, Dhaanish Ahmed college of engineering, Padappai, Chennai 601301. \\ Tamilnadu \\ ${ }^{3}$ Professor and HoD, Aerospace engineering department, Periyar Maniammai University, \\ Vallam, Thanjavur, Tamilnadu.
}

\begin{abstract}
Each material has its own effect and behavior on external impacts like heat, force, tension, compression, torsion etc. It is important to study and analyze these behaviors before selecting a material for an engineering application in the design aspects itself. If predicted values analyzed by both mathematical and software are available it is easy to get the reliable details in the pre design itself. By this one can ensure the safety of the component and the system also. In this investigation, the effects of torsional loads on mild steel round shafts with various diameters and lengths have been analyzed. The additional effects like angle of rotation, rpm and duration also considered to find the optimum predicted value. The data observed by various experiments are analyzed by design of experiments especially by response surface methodology. Minitab software is used for canalization. The data are tabulated and kept for future reference. Noise effect due to the gradual torsional load performed in the gear box and other rotating components is also studied for healthy working environment. The nature and characteristics of material also be explained by this noise analysis.
\end{abstract}

\section{KEY WORDS}

Torsional load, response surface methodology, noise effect, healthy working environment

\section{Nomenclature}

G Modulus of Rigidity, $\quad \mathrm{kN} / \mathrm{m}^{2}$

$\theta \quad$ Angle of twist, 'degrees'

$1 \quad$ Length of shaft, ' $m$ '

d Diameter of shaft, ' $m$ '

$\gamma \quad$ Shear strain

$\tau \quad$ Shear stress, $\quad \mathrm{N} / \mathrm{m}^{2}$

$\mathrm{R} \quad$ Outer radius, ' $\mathrm{m}$ '

J Torsion constant

$\mathrm{r} \quad$ Rotation - in numbers

g Emery sheet grade - in numbers

$\mathrm{t}$ Tensile load, $\mathrm{kN}$ 


\section{INTRODUCTION}

In material science the torsion is defined as a shear stress produced on metal by applying rotation or by torque and fatigue is the progressive and localized structural damage that occurs when a material is subjected to cyclic loading. Most of the shafts with circular cross sections are used for power transmission. The most common cause of failure in such shafts is fatigue. The rotating components are susceptible to fatigue by the nature of their operation and the fatigue failures are generally of the rotating - bending type. For this, experimental study of shafts with various parameters and analysis are required. Sudden failure leads to Interruption in process, Production loss, System failure, unnecessary time delay and accident. It develops unsafe working condition. To avoid the fore mentioned parameters a pre design torsional effects, failure analysis and reliable data are required. This study implies to evaluate the effect of torsion under repeated cyclic loads on mild steel shafts. The noise produced during the torsional process is affecting the healthy working condition and thereby it reduces the productivity of the testing environment in a large $\mathrm{R}$ \& D sections. It badly irritates the nearby workers, in smaller working areas.

American society of tool and manufacturing engineers (ASTME) in its Tool Engineer's Hand Book ${ }^{[15]}$ stresses about the importance of the Fatigue failure studies and analysis. It also insists that these types of study and analysis are required to improve the safety measures and to develop a safety and noise free environment in the pre design stage itself. R.S. Khurmi ${ }^{[13]}$ in his 'Strength of material book' explained a sequential procedure for the fatigue test to observe the behavior of materials under various parameters. The fatigue failure is an unexpected and catastrophic failure occurs in various stages ${ }^{[6]}$. It defines the fatigue and details about the causes for fatigue failures, its types and fatigue life are available for Engineers end use. It shows the relation between the stress and the number of cycles in S-N plot for brittle aluminium with ultimate tensile strength of $320 \mathrm{Mpa}$ and explained the probabilistic nature of fatigue failure. It also gives two earlier accident cases due to fatigue failure -1842 Versailles train derailment due to axle broken and 1954 De Havilland Comet passenger jet air crash caused by the sharp corners around the plane's window openings acted as initiation sites for cracks. The investigation reveals that some preventing or reducing methods are required for fatigue failures. S.Rusz et al ${ }^{[4]}$ evaluated the fatigue properties of micro alloyed steels with a use of samples in initial stage and after selected heat treatment on stainless steel bar with diameter $11.8 \mathrm{~mm}$ and length of $220 \mathrm{~mm}$ in Universal bending machine and fatigue testing machine. Fatigue test of micro alloyed 23MnB4 steel was completed by metallographic and fracture analysis. From this, it can be understood that fatigue properties of materials is depended on heat treatment.

M.J.Reid ${ }^{[3]}$ had done his experiments on failures of sugar mill roll shaft due to fatigue. Theoretical analysis of shaft stresses and fatigue stress concentration factors have been carried out to determine the parameters such as present shaft design, machine properties, material specifications and the shell assembly techniques. From the failure investigations it is found that the fracture always has the appearance of a fatigue failure because of the characteristic clamshell lines from the point of the initial cracks followed by parallel failure lines similar to the growth rings on a tree and the initial stress raiser is seldom evident because of subsequent surface damage in the vicinity of the fracture. Pete Hylton ${ }^{[9]}$, in his investigation, stressed that the air craft experienced loss of one wing due to the fatigue failure of the wing - fuselage interface. Prop-whirl flutter can cause just such a failure due to an undamped coupling of an engine and Prop-whirl flutter has always been a difficult phenomenon to analyse. Large finite element models have been utilized to represent air craft wing and nacelle structures and analyse the occurrence of Prop-whirl flutters. It reveals that the introduction of readily available, easy to use, yet highly powerful mathematical analysis tools such as Matlab has changed the analysis process. The breaking a thin steel rod or wire with hands after bending it back and forth several times in the same place and an unbalanced pump impeller resulting in vibration that can cause failure are 
the examples of fatigue stress creation and its effects on shafts. It also clearly states that the fundamental requirements during design and manufacturing for avoiding fatigue failure are different for different cases and should be considered during the design phase itself.

S.K.Bhaumik et al ${ }^{[5]}$ conducted an experiment on a gear box shaft. They found a micro / hairline crack on a low speed hollow shaft of a single stage helical gear box during its service. On observation it was not a catastrophic failure; the shaft was withdrawn from service because of oil leakage. Subsequent investigation revealed that the crack had initiated by fatigue at one of the keyway edges. The problem was further aggravated due to in adequate radius at the keyway edges and rough machining marks. The images, pictures, details of a bolt failure, metal fatigue details, a pump shaft failure, Lorry steering arm and spring failure and a reversed torsional fatigue failure details of a splined shaft from a differential drive gear are available in many literature ${ }^{[18]}$.

\section{EXPERIMENTAL SET UP}

Fatigue failure occurs by the application of cyclic loads and an experimental set up is arranged to observe the data for analysis. Machinery set up with a motor, gear box, sample holding device in which one end is driving and the other end is driven, the breaking load display unit and then the speed variation set up is required to conduct this experiments. Three types of emery cloths (Rough, Medium and Fine) are used to polish the surface of the specimen. A three phase varioc is also used to vary the speed of the motor.Figure1shows the experimental set up.

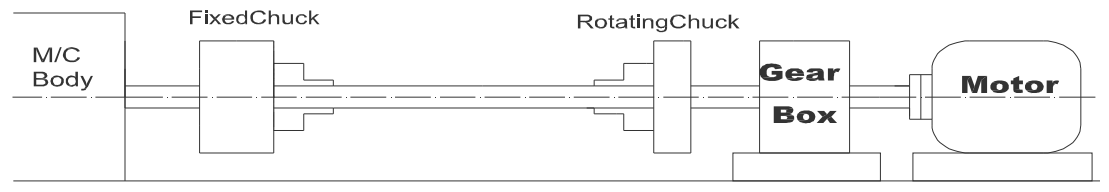

Figure 1 Schematic diagram of experimental set up

Though there are numerous ways of fatigue test available in a laboratory, but the basic principle is the same for all. The most common test is a rotating bar test of cantilever type and beam type. In this test, a number of identical test piece bars (from 8 to 10mm) are made from the same material and tests were conducted one by one. The load is gradually applied to the test piece (This load should not be less than that which can produce a stress equal to $3 / 4$ of the tensile strength of the material up to the elastic limit) by giving rotation. Table 1 gives the details about the machine.

Table 1 Machine Properties

\begin{tabular}{|l|c|l|}
\hline Make & $:$ & Fuel Instruments and Engineers Pvt.Ltd. \\
\hline Model & $:$ & TT -6 \\
\hline Maximum Torque Capacity & $:$ & $60 \mathrm{Nm}$ \\
\hline Torque Ranges & $:$ & $60-30 \mathrm{Nm}$ \\
\hline No. of Div. on Dial & $:$ & 600 \\
\hline Torsion speed & $:$ & $1.5 \mathrm{rpm}$ \\
\hline Clearance between Grips & $:$ & $0-420 \mathrm{~mm}$ \\
\hline Grips for round specimen & $:$ & $4-8,8-12 \mathrm{~mm}$ \\
\hline Motor $(400-440 \mathrm{~V}, 3$ Phase, $50 \mathrm{~Hz})$ & $:$ & $0.5 \mathrm{HP}$ \\
\hline
\end{tabular}


The rotation of the electric motor will sometimes push the test piece downwards and sometimes pull upwards which will reverse in the upper and lower fibers of the test piece. The speed of the motor was indicating the frequency of the stress reversal and it kept constant. It has been experimentally found that after sufficient stress reversals a crack in the form of a ring is formed on the outer surface of the shaft. This crack further developed and extended towards the centre of the test piece till it breaks away. It has also been observed that the speed of the motor (or) in other words the frequency of the stress reversal has no effect on the result.

\section{STATISTICAL TECHNIQUE}

In order to optimize the process, a Central Composite rotatable Design of second order Response Surface Methodology, a full factorial design is established which takes into account all the possible combinations of process parameters. It establishes the mathematical relation of the response surface using the smallest possible number of experiments without losing its accuracy. Table 4 shows the parameter settings for performing the statistical test on degree of significance of process parameters and their interactions. Table 2 shows the specimen details.

Table 2 Specimen Details

\begin{tabular}{|lr|c|l|}
\hline $\begin{array}{l}\text { MATERIAL } \\
\text { Designation } \\
\text { Chemical composition }\end{array}$ & $:$ & $\begin{array}{l}\text { Plain Carbon Steel } \\
\text { C } 40, \text { cold drawn }\end{array}$ \\
& Manganese & $:$ & $0.35-0.45 \%$ \\
\hline SHAPE & $:$ & Round \\
\hline SIZE & & \\
& Diameter & $:$ & $6 \mathrm{~mm}, 8 \mathrm{~mm}$ and $10 \mathrm{~mm}$ \\
\hline Length & $:$ & $250 \mathrm{~mm}, 300 \mathrm{~mm}$ and $350 \mathrm{~mm}$ \\
\hline
\end{tabular}

The selected design matrix shown in Table 3 is a five factor three level Central Composite rotatable designs consisting of 54 sets of coded condition respectively.

Table 3 Parameters and Levels Matrix

\begin{tabular}{|c|c|c|c|c|c|}
\hline \multicolumn{6}{|c|}{ LEVELS AND VARIABLES OF PARAMETERS } \\
\hline \multirow{2}{*}{ Sl.No } & \multirow{2}{*}{ Parameter/Notations/Units } & \multirow{2}{*}{$\begin{array}{l}\text { Coded } \\
\text { values }\end{array}$} & \multicolumn{3}{|c|}{ Parameter levels } \\
\hline & & & -1 & 0 & 1 \\
\hline 1 & DIAMETER/d/mm & $x_{1}$ & 6 & 8 & 10 \\
\hline 2 & ROTATION/r/rpm & $x_{2}$ & 1310 & 1350 & 1390 \\
\hline 3 & LENGTH/l/mm & $x_{3}$ & 250 & 300 & 350 \\
\hline 4 & GRID/G/Nos & $x_{4}$ & 20 & 54 & 120 \\
\hline 5 & TENSILE LOAD/t/kN & $x_{5}$ & 1570 & 2120 & 3580 \\
\hline
\end{tabular}

Response Surface Methodology (RSM) explores the relationships between several explanatory variables and one or more response variables. For five independent variables $x_{1}, x_{2}, x_{3}, x_{4}$ and $x_{5}$ response $\mathrm{Y}$ can be represented as a function of $x_{1}, x_{2}, x_{3}, x_{4}$ and $x_{5}$ as follows.

$$
\mathrm{Y}=f\left(x_{1}, x_{2}, x_{3}, x_{4}, x_{5}\right)
$$


The second order RSM model is adequate which can be represented by the following equation.

$\mathrm{Y}=\beta_{0}+\sum_{i=1}^{k} \beta_{\mathrm{i}} x_{\mathrm{I}}+\sum_{i=1}^{k} \beta_{\mathrm{ii}} x_{\mathrm{i}}^{2}+\sum_{i j}^{k} \beta_{\mathrm{ij}} x_{\mathrm{i}} x_{\mathrm{j}}+\varepsilon$

Where $\beta_{1}(\mathrm{i}=0,1,2 \ldots \mathrm{k})$ are co - efficient that have to be estimated and $\varepsilon$ represents a normally distributed random error that accounts for all source of variability. The following equation is represented the best fit for this experimental data.

$\mathrm{Y}=\mathrm{E}(\mathrm{Y}-\varepsilon)$

$\mathrm{Y}=\hat{\beta}_{0}+\sum_{i=1}^{k} \hat{\beta}_{\mathrm{i}} x_{\mathrm{I}}+\sum_{i=1}^{k} \hat{\beta}_{\mathrm{ii}} x_{\mathrm{i}}^{2}+\sum_{i j}^{k} \hat{\beta}_{\mathrm{ij}} x_{\mathrm{i}} x_{\mathrm{j}}$

where $\hat{\beta}_{0}$ is the estimator of intercept, $\hat{\beta}_{1,} \hat{\beta}_{2}, \ldots \ldots \ldots, \hat{\beta}_{\mathrm{k}}$ are the linear terms, $\hat{\beta}_{11}, \hat{\beta}_{22}$, $\hat{\beta}_{\mathrm{kk}}$ are quadratic terms and $\hat{\beta}_{12}, \hat{\beta}_{13}, \ldots \ldots \ldots \ldots, \hat{\beta}_{(\mathrm{k}-1), \mathrm{k}}$ are the second order interaction terms. 54 experimental runs were conducted. A factorial experiment can be analyzed by using ANOVA or regression analysis. These are relatively easy to estimate the main effect for a factor. Other useful exploratory analysis tools for factorial experiments include main effects plots, interaction plots and a normal probability plot of the estimated effects. Analysis of Variance (ANOVA) is a collection of statistical models and their associated procedures in which the observed variance is partitioned into components due to different explanatory variables. Table 4 illustrates the ANOVA values.

Table 4 Analysis of Variance (ANOVA) results for Torque

\begin{tabular}{|l|c|c|c|c|c|}
\hline Sources of Variation & DF & Seq SS & Adj SS & Adj MS & F-test \\
\hline Regression & 14 & 348336158 & 348336158 & 24881154.2 & $6454442.67^{\mathrm{a}}$ \\
\hline Linear & 5 & 348335971 & 285003 & 57000.7 & 14786.60 \\
\hline Interaction & 9 & 188 & 188 & 20.9 & 5.41 \\
\hline Residual Error & 39 & 150 & 150 & 3.9 & - \\
\hline Lack of fit & 10 & 73 & 73 & 7.3 & 2.71 \\
\hline Pure Error & 29 & 78 & 78 & 2.7 & - \\
\hline Total & 53 & 348336309 & - & - & - \\
\hline
\end{tabular}

Considering five parameters such as diameter, rotation, length, grid and the tensile load, 54 numerical experiments have been carried out to determine the torque value to the failure of the particular specimen. The actual values of the parameters, the measured and predicted values of the torque are tabulated. There is an average error of 0.7465 percent in the predicted value is observed.

$\%$ of error $=\frac{\tau \text { measured }-\tau \text { predicted }}{\tau \text { predicted }} \times 100$

Where $\tau$ measured $=$ the experimental value of torque in $(\mathrm{Nm})$ and $\tau$ predicted $=$ the calculated value of torque in $(\mathrm{Nm})$

The experimental data were analyzed using the Minitab software which gives the output in tabular form and was used to calculate the values of these co - efficient. For the required response, all the 54 values for torque mode and the second order general mathematical model for the five factors are given to the software as input. The significance of co - efficient was 
evaluated. The final mathematical model of Torque mode as determined by above analysis in natural scale is given below

Torque $=-9542.91+719.88 \mathrm{~d}+4.24 \mathrm{r}-2.451-3.88 \mathrm{G}+1.71 \mathrm{t}-0.04 \mathrm{~d} \times \mathrm{l}+0.21 \mathrm{~d} \times \mathrm{G}$

where $\mathrm{d}=$ Diameter $(\mathrm{mm}), \mathrm{r}=$ Rotation (in numbers), $\mathrm{l}=$ Length $(\mathrm{mm}), \mathrm{G}=$ Grid Number, $\mathrm{t}=$ Tensile load $(\mathrm{kN})$ Significant at 5 percent level, SS - Sum of squares, DF - Degrees of Freedom, MS - Mean Square F $($ Table Value $)=2.01$

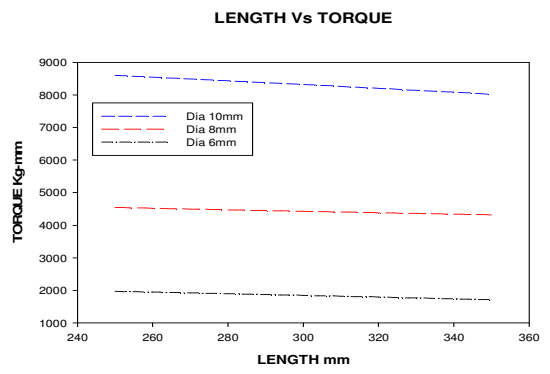

Figure 2 Torque vs Length comparison chart

Figure 2 illustrates the relationship between the length of the shaft and the torque required to break during torsion. It also shows the variation of torque values as per the diameter of the shafts. More diameter is needed more torque for break. The length of the shaft plays a vital role in the requirement of torque to fail. Higher length requires lesser torque than the shorter one.

Figure 3 shows that the rotation of the motor is directly proportional to the torque. The principal transmission shaft performance specifications are power and speed. The effect of torque is directly proportional to the angular velocity at the surface. i.e torque T $\alpha \omega$ where $\omega$ is the angular velocity. But $\omega$ depends upon the speed. So if speed increases correspondingly $\omega$ as well as T will increase. Thus the curve shows the increased slope with the increase in speed

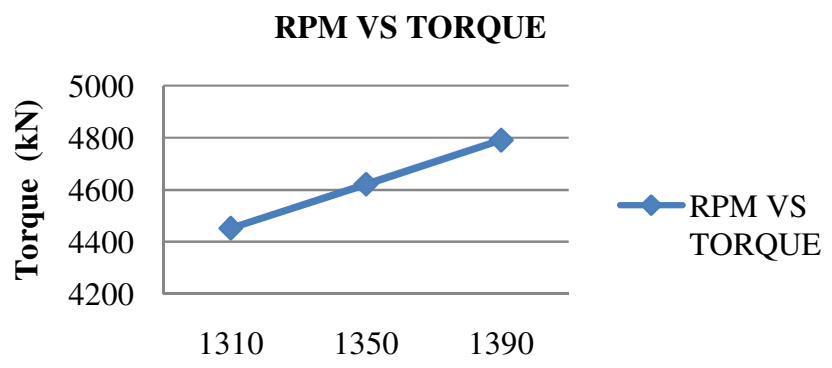

Figure 3 Variation of torque with respect to the rotation of motor

\section{SAFETY CONSIDERATION}

Any failure analysis ends with a safety consideration. Since fatigue failure is an unexpected, catastrophic event it is to be considered as one of the major factor in safety aspects. Sudden failure leads to interruption in process, production loss, system failure, accident and development of unsafe working condition. To avoid such things a pre design failure analysis is must. Unsafe act and unsafe condition are the two main causes of accidents. In this, the unsafe condition starts 
from the design stage itself. Tool Engineers Hand Book ${ }^{[25]}$ published by American Society of Tool and Manufacturing Engineers (ASTME) gives an important note to the Design Engineers as follows: "Experience has shown that notches, sharp changes of section and other forms of stress raisers are dangerous to metals in applications involving repeated stress. Some Engineers neglect to take stress raisers into consideration in design and inspection with the result that a number of avoidable fatigue failures occur. From this statement it is clearly observed that a pre design analysis of fatigue failure needs before design". This research and analysis are the pre design one and the data are more useful to a Design Engineers for their anytime reference to select an appropriate and optimum value to improve the factor of safety as well as the safety to provide an accident free working environment. From the experimental values, it is easily observed that a $6 \mathrm{~mm}$ diameter mild steel shaft with $300 \mathrm{~mm}$ length at 1350rpm withstand to a torque load of 2220 $\mathrm{Kg}-\mathrm{mm}$. At the same time an $8 \mathrm{~mm}$ shaft with the same parameters can withstand more torque load i.e. $4595 \mathrm{Kg}-\mathrm{mm}$. So selection of $8 \mathrm{~mm}$ instead of $6 \mathrm{~mm}$ improves the factor of safety and ensures the safety in the design stage itself.

\section{NOISE ANALYSIS}

Moving parts in a torsion testing machine release tolerable noise level on nil loads. They produce gradually developed noise and vibration depending upon the material, size and length of the rod which is loaded for torsion testing. Table 5 illustrates the rotation requirements for shear, noise level measurements and torque levels

Table 5 Rotation requirements for shear, noise level and torque values

\begin{tabular}{|c|c|c|c|c|c|}
\hline $\begin{array}{c}\text { Diameter } \\
(\mathrm{mm})\end{array}$ & $\begin{array}{c}\text { Length } \\
(\mathrm{mm})\end{array}$ & $\begin{array}{c}\text { Rotation required } \\
\text { for break (degrees) }\end{array}$ & $\begin{array}{c}\text { Number of } \\
\text { rotation }\end{array}$ & $\begin{array}{c}\text { Noise level } \\
(\mathrm{dB})\end{array}$ & $\begin{array}{c}\text { Torque } \\
\mathrm{Kg}-\mathrm{mm}\end{array}$ \\
\hline 10 & 250 & 2710 & 7.52 & 98 & 8603 \\
\hline 10 & 300 & 2460 & 6.83 & 85 & 8320 \\
\hline 10 & 350 & 2230 & 6.19 & 83 & 8023 \\
\hline
\end{tabular}

Number of rotation increases according to the characteristics of the material to break. It may vary by the chemical composition, heat treatment through which the material is formed, the nature of material, surface condition and physical and chemical properties of the material. In this study the behavior of three mild steel round rod samples with same diameter $(10 \mathrm{~mm})$ and different lengths $(250 \mathrm{~mm}, 300 \mathrm{~mm}$ and $350 \mathrm{~mm}$ ) has investigated for noise effect. The samples required several rotations for break and the noise produced in gear box is gradually increases with increase of rotation. Noise level is measured for each rotation and tabulated.

\section{RESULTS AND DISCUSSIONS}

Three samples were experimented for noise effects with increase in number of rotations up to the failure level. Figure 3 reveals that the noise effect on number of rotations which are the major factors for shear of material in torsion process and also gave a comparison illustration with other results. Rotations vary with the material characteristics and sizes. Figure 4 shows the results of three samples of $10 \mathrm{~mm}$ diameter with various lengths namely $250 \mathrm{~mm}, 300 \mathrm{~mm}$ and $350 \mathrm{~mm}$ were illustrated. Curves show that the noise level slowly increases per rotation and increased randomly after fourth rotation because the work piece tried to resist the torsion effect. 


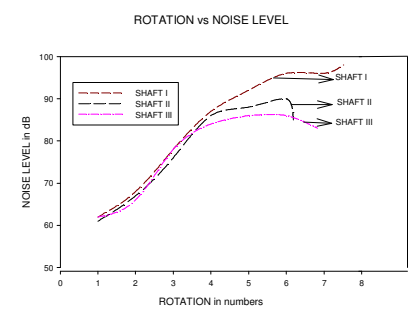

Figure 4 Rotation vs Noise level

At the end of the process in $250 \mathrm{~mm}$ sample gives the high noise level. This shows there is a sudden increase of noise level when shear off takes place. It is observed that if the work piece is tough in nature it develops more noise intensity when it shears. So the end shape of the shaft I curve indicates that the work piece is tough in nature and its usage should be restricted in the working environment because it creates high noise and it affects the nearby worker's health. Like this the material quality of the other shafts can be identified as coarse for shaft II and smooth for shaft II. From this method one ,

NOISE LEVEL vs TORQUE

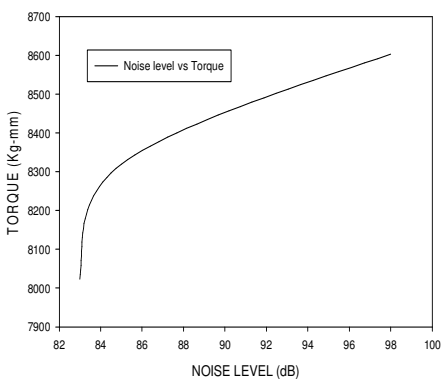
erial quality.

Figure 5 Noise level variations with Torque

From the figure 5 it is observed that the noise level produced is increased by torque required to break the rod during torsion. The noise level shows a sudden increase in beginning and gradually increases afterwards as per the material size especially the diameter. The same experiment may extend to other ferrous and non ferrous materials with different diameters, lengths for analysis. The capacity of the machine and the maintenance details also get from the plots. If the machine has more capacity than the required one, there is a chance for reduction in number of rotation and the noise level production. If the maintenance schedule and the procedure are followed strictly then the nature of working capacity of the machine parts are smooth and this will help to reduce the noise level as well as the number of rotations considerably. Table 6 gives the noise level details.

Table 6 Noise measurement

\begin{tabular}{|c|c|c|c|}
\hline \multirow{2}{*}{$\begin{array}{c}\text { Number of } \\
\text { rotation }\end{array}$} & \multicolumn{3}{|c|}{ Length (mm) } \\
\cline { 2 - 4 } & Shaft I (250) & Shaft II (300) & Shaft III (350) \\
\hline 1 & 62 & 61 & 62 \\
\hline 2 & 68 & 67 & 66 \\
\hline 3 & 78 & 76 & 78 \\
\hline 4 & 87 & 86 & 84 \\
\hline 5 & 92 & 88 & 86 \\
\hline 6 & 96 & 90 & 86 \\
\hline 6.19 & - & - & 83 \\
\hline 6.83 & - & 85 & - \\
\hline 7 & 96 & - & - \\
\hline 7.52 & 98 & - & - \\
\hline
\end{tabular}




\section{CONCLUSIONS}

Torque values required to break mild steel round shafts with various diameters and lengths has been studied, analyzed and recorded in this research. A design Engineer can use these values for his design calculations to improve the safety aspects of his design. By this, the life of the equipments as well as the performance of the process and outputs can be improved in the pre design itself. A noise analysis with number of rotations helps to predict the quality of the material, machine capacity and its working condition and maintenance details. Comparison study between various ferrous and non ferrous materials is also possible.

\section{REFERENCES}

[1] A.H. Bonnett (2000) 'Root cause AC motor failure analysis with a focus on shaft failures', IEEE Trans. Industry Application, Vol 36, Issue 5, pp 327-331.

[2] Cyndi Nyberg, (2007) 'Understanding Factors That Cause Shaft Failures', Electrical Apparatus Service Association, Inc. Vol 6, pp 24-27.

[3] M. I. Reid (1988) 'Analysis of the causes of recent roll shaft failures in natal sugar mills', The South African Sugar Technologists' Association pp 74-78.

[4] S. Rusz, L. Cizek, P. Filipec, M. Pastrnak (2008) 'Fatigue failure of micro-alloyed 23MnB4 steel Journal of Achievements in Materials and Manufacturing Engineering,' volume 31 issue 2, pp 243247.

[5] S.K. Bhaumik et al (2002) 'Fatigue failure of a hollow power transmission shaft', Engineering Failure Analysis, Vol 9, pp 457-467.

[6] Shine U P, EMS Nair. (2008) 'Fatigue Failure of Structural Steel - Analysis Using Fracture Mechanics', World Academy of Science, Engineering and Technology, Vol 46, pp 616-619.

[7] T.Nimali Medagedara (2004) 'Comparison of experimental and Finite Element results for ElasticPlastic Stress/Strain behavior of notched shaft under multi axial loading', International Symposium of Research Students on Materials Science and Engineering Chennai, India, pp20-22, 2004,

[8] C. Colquhoun, J.Draper (2000) 'Fatigue Analysis of an FEA Model of a Suspension Component, and Comparison with Experimental Data', NAFEMS Seminar Vol 9 pp112-115.

[9] Pete Hylton (2006) 'Analyzing a simple prop-whirl-flutter model using modern analysis tools', IJMEINTERTECH Conference 2006.

[10] Paul Dvorak (2001) 'How to get a better handle on fatigue', Published on Machine Design Created 07/12/2001 - 02:00

[11] Bob Williams (2005) 'Will the design survive? Ask Fatigue Analysis', Published on Machine Design Created 05/19/2005 - 02:00.

[12] M. M. Khonsari, E. R. Booser (2008) 'Avoiding Stick-Slip Chatter in Low-Speed Bearings', Published on Machine Design Created 04/10/2008 - 02:00.

[13] R.S.Khurmi (2010) ,'Strength of Materials,' S.Chand Publications reprint 2010 Multicolor Edition pp 842 - 844.

[14] Shaft Analysis - Lecture 18 (2009), Martin School of Engineering, pp 473 - 478.

[15] Tool Engineers Hand Book by American Society of Tool \& Manufacturing Engineers (ASTME) Edition 2 Section 90 pp 17.

[16] Neville Sachs (2009) 'Root cause failure analysis - Understanding mechanical failures', The Plant Maintenance Resource Center Copyright 1996-2009.

[17] D. Alfred Hancq 'Fatigue Analysis Using ANSYS', AnsysInc.com

[18] Material Engineering Component failure museum website

[19] www.Wikipedia.com - the free encyclopedia. 


\section{Authors}

N.Boominathan has completed his B.E, Mechanical engineering degree in Thiagarajar college of engineering, Madurai and M.E., Industrial safety engineering in Bharatth Niketan engineering college, Aundipatti. Now he is doing his research work in the field of Industrial noise at Periyar Maniammai university, Thanjavur. He has 25 years industrial experience and 9 years teaching experience

G.K. Vijayaraghavan, B.E, M.Tech, $\mathrm{PhD}$ is currently working as Adviser, Dhaanish Ahmed College of Engineering, Padappai, Chennai. He has obtained his M.Tech from IIT Madras and $\mathrm{PhD}$ from NIT, Durgapur in the area of Thermography NDT. He has been in the teaching field for more than 18 years. He is one of the editorial board members of 3 international journals and has reviewed many journal papers. He has authored more than 16 textbooks in the area of Mechanical Engineering which are being well received. He has received the "Best Educationalist Award" from International Institute of Engineering \& Management, New Delhi in 2014; "The Best Principal in Engineering College 2014 Award" from Education Today Publications, Chennai.

Dr. R. Kathiravan is presently working as a Professor in Aerospace Engineering department and Director for Center of Excellence for Training and research in Automation Technology (CETAT) in Periyar Maniammai University, Vallam, Thanjavur. He received his Doctorate degree from Indian Institute of Technology Roorkee (IIT Roorkee) and obtained master degree in Thermal Power Engineering from Annamalai University, Chidambaram and Bachelor degree in Mechanical Engineering from Madurai Kamaraj University, Madurai, Tamilnadu state, India. $\mathrm{He}$ is having 20 years of experience in both teaching as well as Industry. He was given a special training on Industrial Automation Technology by $\mathrm{M} / \mathrm{S}$ Bosch Rexroth India at their Mysore centre. He published his 10 research papers on well
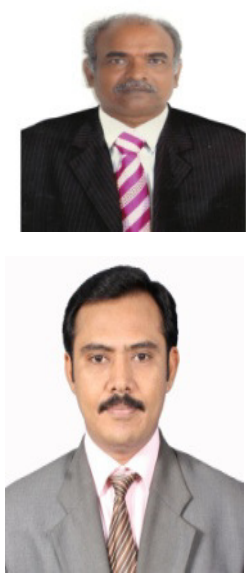
refereed international journals like ASME transactions, Elsevier and Taylor \& Francis Publications etc., and 2 in national Journals. He is a life member of IAENG, ISTE, and SSWR 